\title{
CORRECTION
}

\section{Correction to: The clinician's guide to $p$ values, confidence intervals, and magnitude of effects}

Mark R. Phillips (D), Charles C. Wykoff, Lehana Thabane (D), Mohit Bhandari (D), Varun Chaudhary (D) and for the Retina Evidence Trials InterNational Alliance (R.E.T.I.N.A.) Study Group*

(c) The Author(s), under exclusive licence to The Royal College of Ophthalmologists 2021

Eye; https://doi.org/10.1038/s41433-021-01914-2

Correction to: Eye https://doi.org/10.1038/s41433-021-01863-w, published online 26 November 2021
In this article the middle initial in author name Sophie J. Bakri was missing. 